\title{
A two-step strategy for removing over-the-scope clip buried in contact with the heart
}

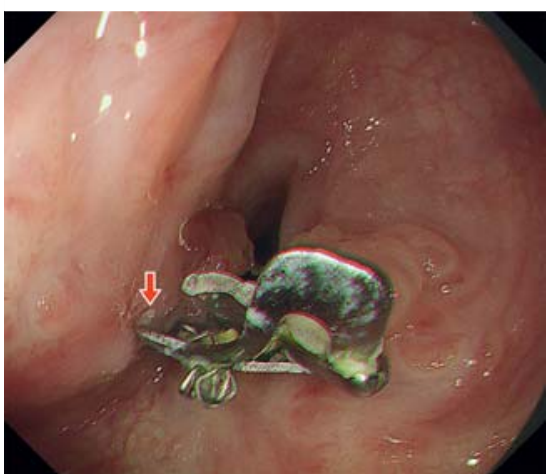

Fig. 1 The over-the-scope clip caused esophageal stenosis. The oral part of the clip was buried in the esophageal anterior wall (arrow)

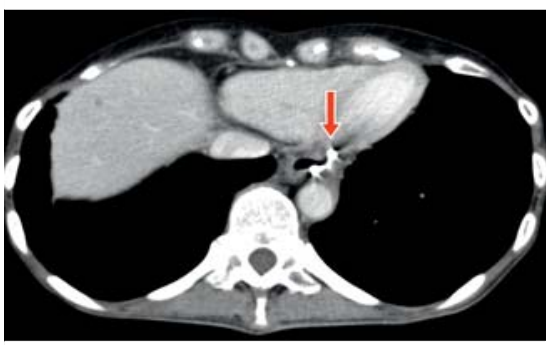

Fig. 2 Computed tomography revealed that the edge of the over-the-scope clip was in contact with the heart (arrow).

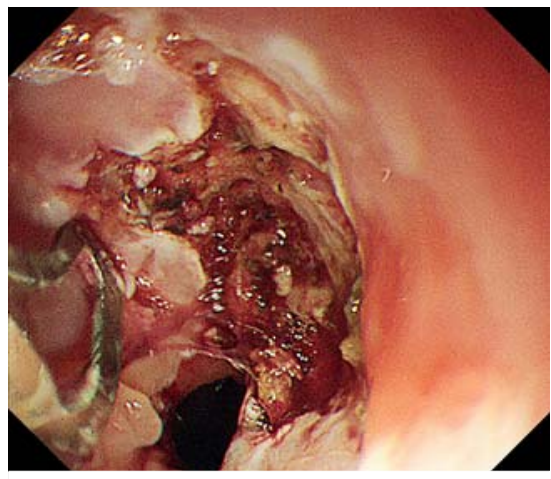

- Fig. 3 The anal part of the over-thescope clip was detached.

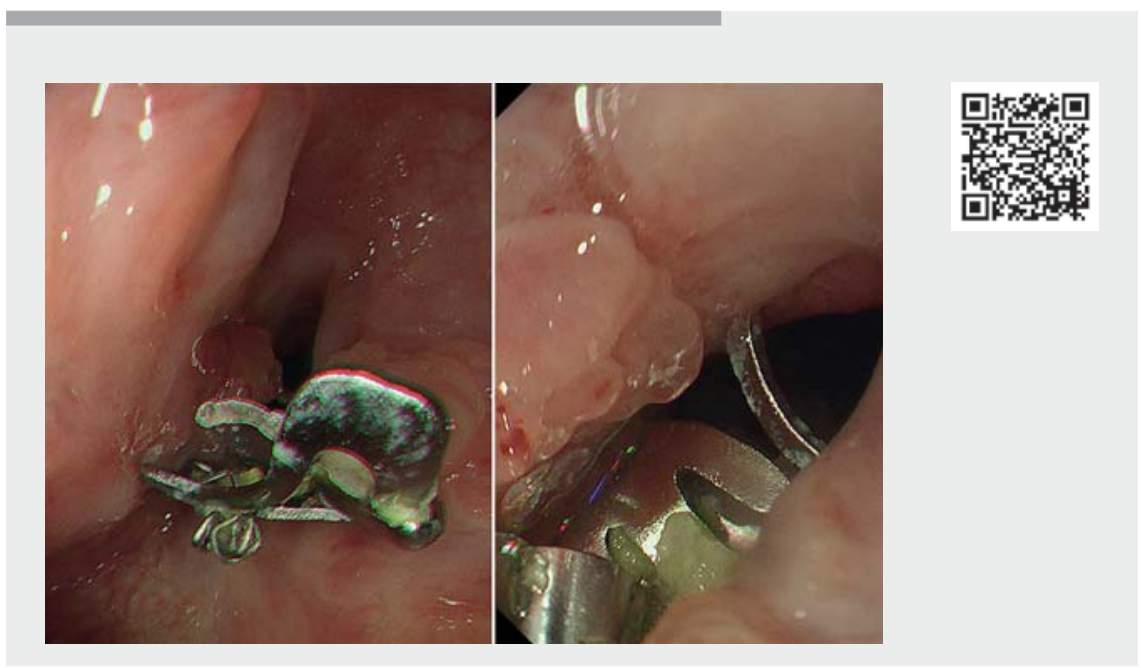

Video 1 An over-the-scope clip, buried in the esophageal wall, was endoscopically removed using a two-step strategy.

An over-the-scope (OTS) clip allows tight endoscopic closure of gastrointestinal perforation [1,2]. However, OTS clips remain in vivo for long periods. Several devices were reportedly useful for OTS clip removal $[3,4]$, but these were not commercially available in Japan. A method for removing OTS clips using an existing device was previously reported [5]. We encountered a case wherein the OTS clip was buried and in contact with the heart ( $\triangleright$ Video 1 ).

A 53-year-old woman underwent robotassisted laparoscopic total gastrectomy for gastric cancer. Endoscopic closure using an OTS clip was attempted following suture failure of the esophagus on postoperative Day 6. However, the esophageal wall was not successfully closed. She underwent open thoracic mediastinal and pericardial drainage on postoperative Day 13. The esophageal fistula was closed with a covered metal stent on postoperative Day 14 . The stent was removed on postoperative Day 34 after her general condition improved. She then complained of dysphagia and on esophagogastroduodenoscopy was found to have esophageal stenosis due to the buried OTS clip ( $\vee$ Fig. 1 ). The oral part of the clip was buried in the esophageal anterior wall ( $\triangleright$ Fig. 1, arrow), and the edge of the clip was seen to be in contact with the heart on computed tomography (॰ Fig. 2).

The esophageal mucosa and submucosal fibrosis around the anal part of the clip were incised using FlushKnife BT-S (1.5 mm, DK2620]; Fujifilm Medical, Tokyo, Japan). The OTS clip was detached except for the oral part ( $\vee$ Fig. 3 ). The oral part of the clip detached spontaneously 19 days after the procedure ( Fig. 4, white arrow), but the anal parts became buried again due to mucosal regeneration ( $\triangleright$ Fig. $\mathbf{4}$, red arrows). These parts were detached again, and the OTS clip was removed entirely ( $\triangleright$ Fig.5). Our approach can be useful when dedicated devices are not available; however, this approach can be more complicated and riskier.

Endoscopy_UCTN_Code_CPL_1AH_2AJ 


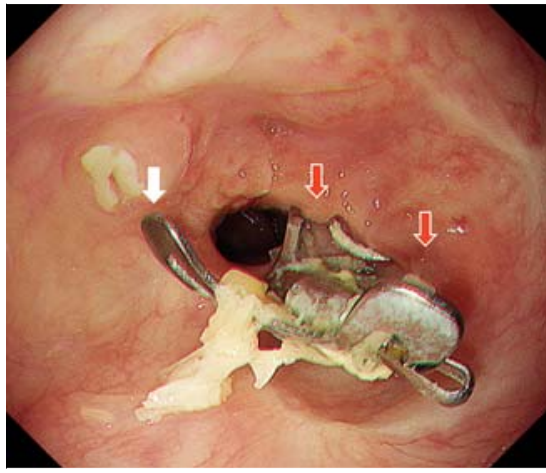

-Fig. 4 The over-the-scope clip was detached (white arrow), but the anal parts of the clip became buried again due to mucosal regeneration (red arrows).

Acknowledgments

The authors thank Editage (www.editage.com) for English language editing.

\section{Competing interests}

The authors declare that they have no conflict of interest.

The authors

\section{Hirohisa Sakurai ${ }^{1}$, Takashi Kanesaka ${ }^{1,2}$, \\ Masaaki Yamamoto ${ }^{3}$, Takeshi Omori ${ }^{3}$, Yasuhiro Tani ${ }^{1}$, Tomoki Michida ${ }^{1}$, Ryu Ishihara ${ }^{1}$}

1 Department of Gastrointestinal Oncology, Osaka International Cancer Institute, Osaka, Japan

2 Department of Gastroenterology and Hepatology, Osaka University Graduate School of Medicine, Suita, Japan

3 Department of Gastroenterological Surgery, Osaka International Cancer Institute, Osaka, Japan

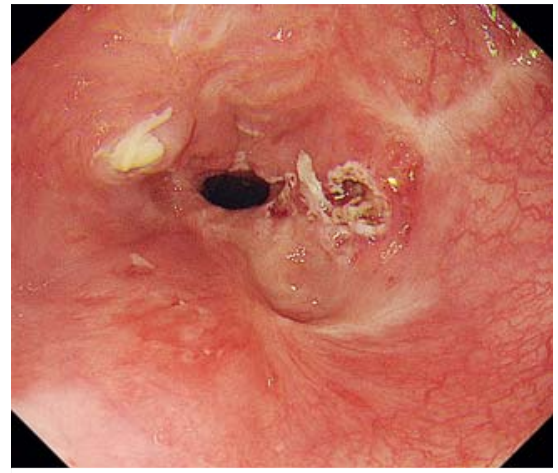

Fig. 5 The over-the-scope clip was removed entirely.

\section{Corresponding author}

\section{Takashi Kanesaka, MD}

Department of Gastrointestinal Oncology, Osaka International Cancer Institute, 3-1-69, Otemae, Chuo-ku, Osaka, 541-8567, Japan takashikanesaka@gmail.com

\section{References}

[1] Kirschniak A, Traub F, Kueper MA et al. Endoscopic treatment of gastric perforation caused by acute necrotizing pancreatitis using over-the-scope clips: a case report. Endoscopy 2007; 39: 1100-1102

[2] Parodi A, Repici A, Pedroni A et al. Endoscopic management of $\mathrm{Gl}$ perforations with a new over-the-scope clip device (with videos). Gastrointest Endosc 2010; 72: 881886

[3] Bauder M, Meier B, Caca K et al. Endoscopic removal of over-the-scope clips: clinical experience with a bipolar cutting device. U Eur Gastroenterol J 2017; 5: 479-484
[4] Fähndrich M, Sandmann M, Heike M. Removal of over the scope clips (OTSC) with an Nd:YAG Laser. Z Gastroenterol 2011; 49 : 579-583

[5] Sakurai H, Shichijo S, Takeuchi Y et al. Endoscopic removal of an over-the-scope clip using endoscopic submucosal dissection technique. Endoscopy 2020. doi:10.1055/a1293-6637

\section{Bibliography}

Endoscopy 2022; 54: E502-E503

DOI 10.1055/a-1625-5805

ISSN 0013-726X

published online 15.10 .2021

(c) 2021. Thieme. All rights reserved.

Georg Thieme Verlag KG, Rüdigerstraße 14,

70469 Stuttgart, Germany

\section{ENDOSCOPY E-VIDEOS}

https://eref.thieme.de/e-videos

回局 Endoscopy E-Videos is an open access online section, 自触: reporting on interesting cases and new techniques in gastroenterological endoscopy. All papers include a high quality video and all contributions are freely accessible online. Processing charges apply (currently EUR 375), discounts and wavers acc. to HINARI are available.

This section has its own submission website at https://mc.manuscriptcentral.com/e-videos 